\title{
Pleiotropic regulation of a glucose-specific PTS in Clostridium acetobutylicum for high-efficient butanol production from corn stover without detoxification
}

\author{
Youduo Wu' ${ }^{1}$, Yidi Bai ${ }^{1}$, Daojing Zhang ${ }^{2}$, Chi Cheng ${ }^{1}$, Lijie Chen ${ }^{1}$, Fengwu Bai ${ }^{3}$ and Chuang Xue ${ }^{1 *}$
}

\begin{abstract}
Background: Corn stover (CS) is evaluated as the most favorable candidate feedstock for butanol production via microbial acetone-butanol-ethanol (ABE) fermentation by Clostridium acetobutylicum. By independent acid pretreatment and enzymatic hydrolysis, fermentable sugars (mainly glucose and xylose) were released, of which glucose was naturally utilized as the most preferred carbon source by C. acetobutylicum. However, the ABE fermentation using corn stover hydrolysate (CSH) without detoxification is typically limited to poor sugars utilization, butanol production and productivity. In the presence of pretreatment-derived inhibitors, the intracellular ATP and NADH, as important factors involved in cell growth, solventogenesis initiation and stress response, are exceedingly challenged owing to disrupted glucose phosphotransferase system (PTS). Therefore, there is a necessity to develop effective engineering approaches to overcome these limitations for high-efficient butanol production from CSH without detoxification.
\end{abstract}

Results: PTS-engineered C. acetobutylicum strains were constructed via overexpression and knockout of gene g/cG encoding glucose-specific PTS IICBA, which pleiotropically regulated glucose utilization, cell growth, solventogenesis and inhibitors tolerance. The PTS ${ }^{\mathrm{GlG}}$-overexpressing strain exhibited high fermentation efficiency, wherein butanol production and productivity was $11.1 \mathrm{~g} / \mathrm{L}$ and $0.31 \mathrm{~g} / \mathrm{L} / \mathrm{h}$, compared to those of $11.0 \mathrm{~g} / \mathrm{L}$ and $0.15 \mathrm{~g} / \mathrm{L} / \mathrm{h}$ with the PTSGlCG-deficient strain. During CSH culture without detoxification, the PTS ${ }^{G l G G}$-overexpressing strain exhibited desirable inhibitors tolerance and solventogenesis with butanol production of $10.0 \mathrm{~g} / \mathrm{L}$, increased by $300 \%$ and $400 \%$ compared to those of 2.5 and $2.0 \mathrm{~g} / \mathrm{L}$ with the control and PTS GlcG-deficient strains, respectively. As a result of extra glucose and $10 \mathrm{~g} / \mathrm{L} \mathrm{CaCO}_{3}$ addition into $\mathrm{CSH}$, butanol production and productivity were further maximized to $12.5 \mathrm{~g} / \mathrm{L}$ and $0.39 \mathrm{~g} / \mathrm{L} / \mathrm{h}$. These validated improvements on the PTS GlcG-overexpressing strain were ascribed to not only efficient glucose transport but also its cascading effects on intracellular ATP and NADH generation, solventogenesis initiation and inhibitors tolerance at the exponential growth phase.

Conclusion: The PTS GluG regulation could be an effective engineering approach for high-efficient ABE fermentation from lignocellulosic hydrolysates without detoxification or wastewater generation, providing fundamental information for economically sustainable butanol production with high productivity.

Keywords: Clostridium acetobutylicum, Corn stover, PTS regulation, Inhibitor tolerance, Butanol productivity

\footnotetext{
*Correspondence: xue.1@dlut.edu.cn

${ }^{1}$ School of Bioengineering, Dalian University of Technology, No 2

Linggong Road, Dalian 116024, China

Full list of author information is available at the end of the article
} 


\section{Background}

Considering the worldwide depletion of fossil fuel resources, fluctuating crude oil prices as well as growing environmental concerns, sustainable butanol production via clostridial acetone-butanol-ethanol (ABE) fermentation is arousing intensive attention due to the unique physicochemical properties of butanol as a promising substitute for fossil-based energy [1-3]. Corn stover (CS) is well accepted as the most favorable candidate feedstock for sustainable $A B E$ fermentation due to its widespread availability and high residue yield [4-6]. Followed by indispensable acid pretreatment and enzymatic hydrolysis, fermentable sugars (mainly glucose and xylose) are released from CS [4, 7], of which glucose is utilized as the most preferred carbon source. Although $\mathrm{H}_{2} \mathrm{SO}_{4}$-pretreatment is cost-effective and widely used for preparing corn stover hydrolysate $(\mathrm{CSH})$ at industrial scale, the major drawback of this pretreatment process is the formation of degradation products such as weak acids, furan derivatives and phenolic compounds, which exhibit combined toxicities on clostridia $[4,7]$. As a result, the fermentative process is severely inhibited without apparent sugar utilization, cell growth or solventogenesis, thus making butanol production from lignocellulosic feedstocks less sustainable and cost-competitive.

In recent years, numerous efforts have been made on development of pretreatment and detoxification methods, butanol recovery techniques, as well as strain reinforcements via mutagenesis, genetic manipulation and metabolic perturbations [8-17]. Particularly, significant improvements have been achieved with engineered solventogenic strains by either eliminating carbon catabolite repression or enhancing xylose metabolism. However, these genetically engineered strains were tested in synthetic media rather than detoxified lignocellulosic hydrolysates [11, 14-17]. Until now, of the best available strains for CS-based ABE fermentation, the highest $\mathrm{ABE}$ production and productivity of $26.3 \mathrm{~g} / \mathrm{L}$ and $0.31 \mathrm{~g} / \mathrm{L} / \mathrm{h}$ were achieved with $C$. beijerinckii P260 using over-limed $\mathrm{H}_{2} \mathrm{SO}_{4}$-pretreated $\mathrm{CSH}$, while no fermentation was observed using non-detoxified hydrolysate [18]. Despite physical, chemical or biological detoxification methods developed for eliminating the toxicities of inhibitors, the resulting wastewater emission, energy cost, sugar loss and low productivity remain hurdles for the economic viability and environmental sustainability at industrial scale $[4,7,8,19]$. Therefore, there is a necessity to develop inhibitor-tolerating strains applicable to CSH culture without detoxification or wastewater generation.

When exposed to high levels of inhibitors like HMF and furfural, $C$. acetobutylicum cells are affected by uncoupling cellular functions associated with nutrient transport, cell replication, enzyme catalysis and stress response, resulting in inner accumulation of toxic metabolites and shortage of carbon, energy and reducing power [7]. In addition, ATP and NADH are drained during stress response such as heat shock proteins biosynthesis, efflux pumps and inhibitors transformation, thus shifting metabolism towards acid production to compensate for the decreased ATP supply [20]. Taken together, the significant issues for CHS culture lie in the disruption of glucose-specific PTS as well as ATP- and NADHdraining effects of microbial inhibitors [7]. More recently, micronutrient zinc as medium addictive affected $\mathrm{ABE}$ fermentation at metabolic and transcriptomic levels of C. acetobutylicum [21-23]. The upregulated expression of gene $g l c G$ encoding glucose-specific PTS IICBA led to efficient glucose transport, which evoked cascading effects on cofactors generation, solventogenesis initiation and stress tolerance [22]. Based on these findings, the objective of this work is to develop PTS GlcG $_{\text {-engineered }}$ C. acetobutylicum applicable to CSH culture without detoxification. Finally, PTS ${ }^{\text {GlcG }}$ overexpression exerted pleiotropic roles facilitating CSH culture, and thus could be an effective engineering approach for high-efficient butanol production from lignocellulosic feedstocks.

\section{Results and discussions}

\section{Pleiotropic regulation of PTS ${ }^{\text {GluG }}$ on ABE fermentation}

The mixture of glucose and xylose was first selected as carbon sources by the wild-type strain L7, control strain L7(pPthl), PTS ${ }^{\mathrm{GlcG}}$-overexpressing strain L7(GlcG) and $\mathrm{PTS}^{\mathrm{GlcG}}$-deficient strain $\mathrm{L} 7(\Delta \mathrm{GlcG})$. Comparative profiles and results were illustrated in Fig. 1 and Table 1, respectively. Similar to strain $\mathrm{L} 7,45.6 \mathrm{~g} / \mathrm{L}$ glucose and $8.6 \mathrm{~g} / \mathrm{L}$ xylose were slowly utilized by strain L7(pPthl) with butanol production and productivity of $11.0 \mathrm{~g} / \mathrm{L}$ and $0.18 \mathrm{~g} / \mathrm{L} / \mathrm{h}$. The acetate production achieved the highest level of $4.7 \mathrm{~g} / \mathrm{L}$ at $12 \mathrm{~h}$ and then decreased to $0.8 \mathrm{~g} / \mathrm{L}$ until the end of fermentation. As for strain L7( $\Delta$ GlcG), $46.8 \mathrm{~g} / \mathrm{L}$ glucose and $13.7 \mathrm{~g} / \mathrm{L}$ xylose were simultaneously consumed, by which xylose utilization was promoted while little difference was observed on glucose utilization, reaching butanol production and productivity of $11.0 \mathrm{~g} / \mathrm{L}$ and $0.15 \mathrm{~g} / \mathrm{L} / \mathrm{h}$. In addition, less than $2.5 \mathrm{~g} / \mathrm{L}$ acetate was detected during the whole fermentation. These observations were identical to the results as recently reported [11], wherein disrupting PTS ${ }^{\text {GlcG }}$ facilitated simultaneous utilization of glucose, xylose and arabinose by C. acetobutylicum. During batch culture with strain L7(GlcG), $46.6 \mathrm{~g} / \mathrm{L}$ glucose was rapidly depleted within $24 \mathrm{~h}$, achieving an average consumption rate of $1.94 \mathrm{~g} / \mathrm{L} / \mathrm{h}$, compared to those of 0.84 and $0.89 \mathrm{~g} / \mathrm{L} / \mathrm{h}$ from strains $\mathrm{L} 7$ (pPthl) and $\mathrm{L} 7(\Delta \mathrm{GlcG})$, respectively. However, only $5.3 \mathrm{~g} / \mathrm{L}$ xylose was utilized due to rapid butanol production up to $11.1 \mathrm{~g} / \mathrm{L}$ and its severe toxicity on cells. Finally, butanol 

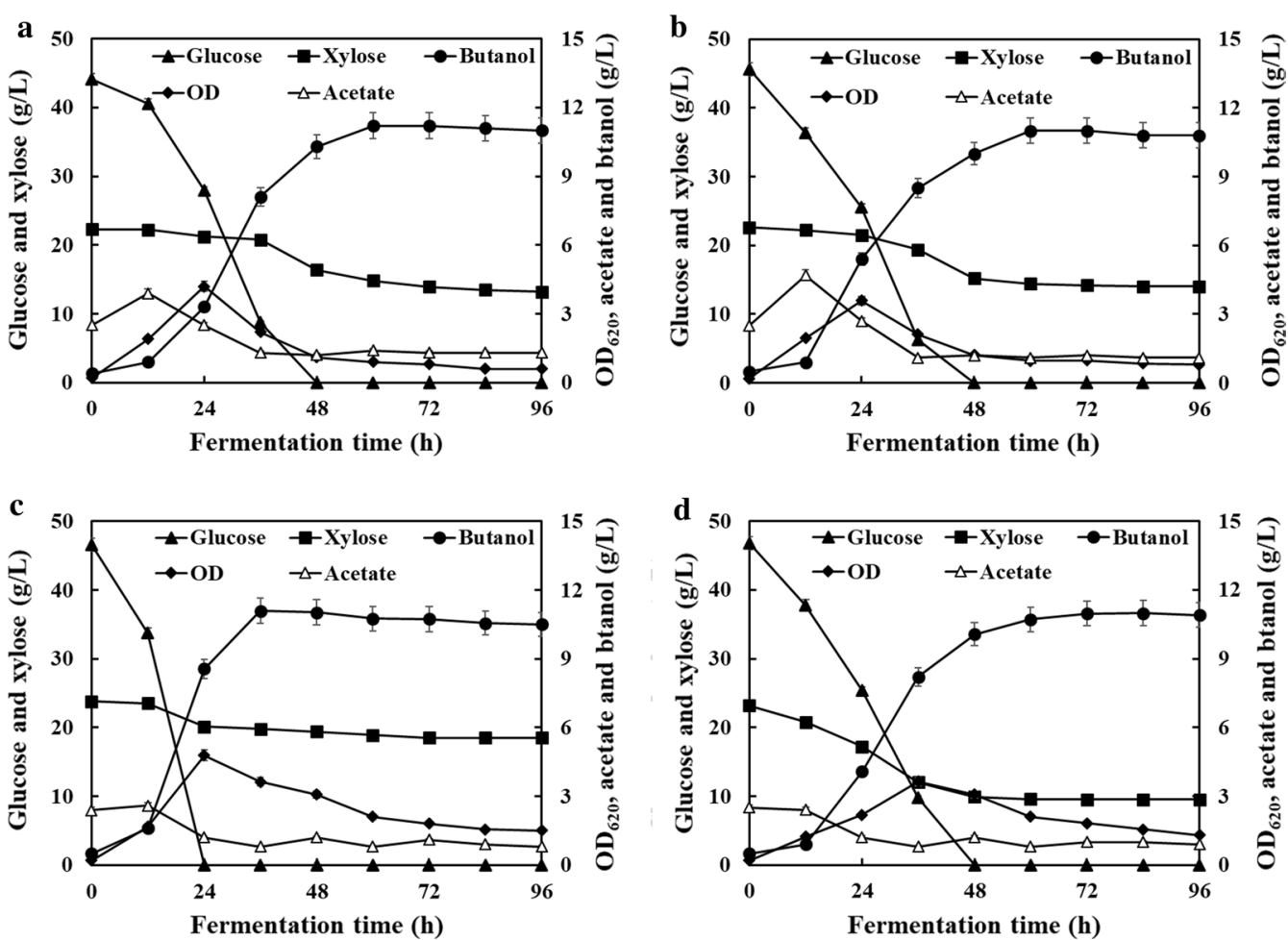

Fig. 1 PTS GlcG-mediated regulation on ABE fermentation using glucose/xylose mixture as carbon sources by strains of a $C$. acetobutylicum $L 7 ; \mathbf{b} C$. acetobutylicum L7(pPthl); c C. acetobutylicum $\mathrm{L} 7(\mathrm{GlcG}) ; \mathbf{d}$ C. acetobutylicum $\mathrm{L} 7(\Delta \mathrm{Gl} \mathrm{cG})$

productivity of $0.31 \mathrm{~g} / \mathrm{L} / \mathrm{h}$ was greatly increased by $72.2 \%$ and $106.7 \%$ compared to those of 0.18 and $0.15 \mathrm{~g} / \mathrm{L} / \mathrm{h}$ from strains $\mathrm{L} 7(\mathrm{pPthl})$ and $\mathrm{L} 7(\Delta \mathrm{GlcG})$, respectively. In particular, strain $\mathrm{L} 7(\mathrm{GlcG})$ produced only $2.6 \mathrm{~g} / \mathrm{L}$ acetate at $12 \mathrm{~h}$ and grew fast with a peak $\mathrm{OD}_{620}$ of 4.8 at $24 \mathrm{~h}$, compared to that of 3.6 at $36 \mathrm{~h}$ for strain $\mathrm{L} 7(\Delta \mathrm{GlcG})$, indicating PTS ${ }^{\text {GlcG }}$-mediated pleiotropic roles in glucose/ xylose utilization, exponential growth and solventogenesis initiation.

Especially for xylose consumption within the first $36 \mathrm{~h}$ of fermentation, only 2.5 and $3.2 \mathrm{~g} / \mathrm{L}$ xylose were utilized by strains $\mathrm{L} 7$ and L7(pPthl), respectively, indicating that severe carbon catabolite repression on xylose consumption occurred in the presence of glucose. Finally, 6.6 and $5.4 \mathrm{~g} / \mathrm{L}$ xylose were consumed by strains L7 and L7(pPthl) from $36 \mathrm{~h}$ to the end of fermentation. Similarly, as low as $3.7 \mathrm{~g} / \mathrm{L}$ xylose was consumed within the first $24 \mathrm{~h}$ of fermentation by strain L7(GlcG). However, in the absence of glucose, only $1.6 \mathrm{~g} / \mathrm{L}$ xylose was further consumed from $24 \mathrm{~h}$ to the end of fermentation due to the severe inhibition of high butanol concentration ( $>9 \mathrm{~g} / \mathrm{L}$ ). Despite more xylose consumed rapidly by PTS $^{\text {GicG }}$-deficient strain within the first $48 \mathrm{~h}$ in the presence of glucose, the fermentative process remained inefficient due to low butanol yield and prolonged metabolism. Until recently, efficient glucose/xylose culture has been achieved by adding calcium carbonate and zinc sulfate, wherein butanol production and productivity were maximized to $13.9 \mathrm{~g} / \mathrm{L}$ and $0.35 \mathrm{~g} / \mathrm{L} / \mathrm{h}$ [23]. Global transcriptomic and proteomic results showed that $\mathrm{CaCO}_{3}$ and $\mathrm{ZnSO}_{4}$ could act upon overall cellular functions associated with sugar utilization, central carbon metabolism and stress response at global levels [22, 24-26]. Particularly, followed by zinc addition, the expression of gene $g l c G$ was 3.62-fold upregulated at the exponential growth phase of C. acetobutylicum. Additionally, intracellular metabolites analysis showed that central carbon flux was earlier redistributed towards solventogenesis owing to increased supplies of ATP and NADH as driving forces [22]. Hence, fermentation efficiency depends on not only strains used but a rapid shift towards solventogenesis, which was mainly attributed to the coordination of metabolic cues and their cascading effects on C. acetobutylicum.

\section{Enhanced inhibitors tolerance during CSH culture without detoxification}

The basic chemical compositions of unpretreated CS solids were $40.8 \%$ cellulose, $15.2 \%$ hemicellulose, $32.1 \%$ acid insoluble lignin and ash. Followed by acid pretreatment, the pretreated CS solids were mainly composed 
Table 1 Comparative results of batch ABE fermentation by C. acetobutylicum strains

\begin{tabular}{|c|c|c|c|c|c|c|c|c|}
\hline \multirow[t]{2}{*}{ Strain } & \multirow[t]{2}{*}{ Sugar utilized (g/L) } & \multicolumn{5}{|c|}{ Products (g/L) } & \multirow[t]{2}{*}{$Y_{\mathrm{B} / \mathrm{ABE}}(\mathrm{g} / \mathrm{g})$} & \multirow[t]{2}{*}{$P_{\mathrm{B} / \mathrm{ABE}}(\mathrm{g} / \mathrm{L} / \mathrm{h})$} \\
\hline & & Acetate & Butyrate & Acetone & Butanol & Ethanol & & \\
\hline \multicolumn{9}{|c|}{ 7\% glucose/xylose (2:1) mixture as carbon sources } \\
\hline L7 & $44.1 \pm 1.1 / 9.1 \pm 0.9$ & $1.3 \pm 0.2$ & $1.0 \pm 0.2$ & $6.5 \pm 0.4$ & $11.2 \pm 0.5$ & $1.2 \pm 0.1$ & $0.21 / 0.36$ & $0.19 / 0.32$ \\
\hline L7(pPthl) & $45.6 \pm 1.5 / 8.6 \pm 0.8$ & $1.1 \pm 0.1$ & $0.9 \pm 0.1$ & $6.0 \pm 0.3$ & $11.0 \pm 0.5$ & $1.8 \pm 0.1$ & $0.20 / 0.35$ & $0.18 / 0.31$ \\
\hline $\mathrm{L} 7(\mathrm{G} \mid c \mathrm{G})$ & $46.6 \pm 1.3 / 5.3 \pm 0.8$ & $0.8 \pm 0.1$ & $0.5 \pm 0.1$ & $6.6 \pm 0.5$ & $11.1 \pm 0.4$ & $1.9 \pm 0.2$ & $0.21 / 0.38$ & $0.31 / 0.54$ \\
\hline $\mathrm{L} 7(\Delta \mathrm{GlcG})$ & $46.8 \pm 1.5 / 13.7 \pm 1.1$ & $0.9 \pm 0.1$ & $0.4 \pm 0.1$ & $6.1 \pm 0.3$ & $11.0 \pm 0.5$ & $1.2 \pm 0.1$ & $0.18 / 0.30$ & $0.15 / 0.25$ \\
\hline \multicolumn{9}{|c|}{ Non-detoxified $\mathrm{H}_{2} \mathrm{SO}_{4}$-pretreated $\mathrm{CSH}$ as carbon sources ${ }^{\mathrm{a}}$} \\
\hline L7 & $15.6 \pm 1.3$ & $2.4 \pm 0.2$ & $2.1 \pm 0.3$ & $1.8 \pm 0.1$ & $2.5 \pm 0.2$ & $0.5 \pm 0.1$ & $0.16 / 0.31$ & $0.07 / 0.13$ \\
\hline L7(pPthl) & $15.2 \pm 1.1$ & $2.8 \pm 0.2$ & $2.3 \pm 0.2$ & $1.7 \pm 0.1$ & $2.5 \pm 0.2$ & $0.5 \pm 0.1$ & $0.16 / 0.31$ & $0.07 / 0.13$ \\
\hline $\mathrm{L} 7(\mathrm{GlcG})$ & $45.4 \pm 1.6$ & $1.3 \pm 0.1$ & $1.1 \pm 0.1$ & $6.0 \pm 0.3$ & $10.0 \pm 0.4$ & $1.3 \pm 0.1$ & $0.22 / 0.38$ & $0.28 / 0.48$ \\
\hline $\mathrm{L} 7(\triangle \mathrm{GlcG})$ & $12.3 \pm 1.4$ & $1.7 \pm 0.2$ & $1.4 \pm 0.2$ & $1.2 \pm 0.1$ & $2.0 \pm 0.1$ & $0.4 \pm 0.1$ & $0.16 / 0.29$ & $0.04 / 0.08$ \\
\hline \multicolumn{9}{|c|}{ Non-detoxified enzymatically $\mathrm{H}_{2} \mathrm{SO}_{4}$-pretreated $\mathrm{CSH}$ as carbon sources } \\
\hline L7 & $16.5 \pm 1.3^{b}$ & $2.6 \pm 0.2$ & $2.2 \pm 0.3$ & $1.4 \pm 0.1$ & $3.0 \pm 0.2$ & $0.4 \pm 0.1$ & $0.18 / 0.29$ & $0.08 / 0.13$ \\
\hline L7(pPthl) & $15.6 \pm 1.0^{\mathrm{b}}$ & $2.9 \pm 0.3$ & $2.3 \pm 0.2$ & $1.5 \pm 0.1$ & $2.7 \pm 0.1$ & $0.5 \pm 0.1$ & $0.17 / 0.30$ & $0.08 / 0.13$ \\
\hline \multirow[t]{4}{*}{$\mathrm{L} 7(\mathrm{GlcG})$} & $34.5 \pm 1.9^{b}$ & $1.8 \pm 0.2$ & $1.5 \pm 0.2$ & $3.9 \pm 0.2$ & $7.2 \pm 0.3$ & $0.9 \pm 0.1$ & $0.21 / 0.35$ & $0.20 / 0.33$ \\
\hline & $45.0 \pm 1.5^{c}$ & $2.7 \pm 0.3$ & $2.1 \pm 0.2$ & $5.6 \pm 0.3$ & $10.0 \pm 0.3$ & $1.0 \pm 0.1$ & $0.22 / 0.37$ & $0.28 / 0.46$ \\
\hline & $52.5 \pm 2.0^{d}$ & $1.5 \pm 0.1$ & $1.2 \pm 0.2$ & $6.6 \pm 0.4$ & $11.0 \pm 0.4$ & $1.6 \pm 0.1$ & $0.21 / 0.37$ & $0.34 / 0.60$ \\
\hline & $60.0 \pm 1.8^{e}$ & $2.1 \pm 0.2$ & $1.7 \pm 0.1$ & $6.7 \pm 0.4$ & $12.5 \pm 0.4$ & $1.8 \pm 0.2$ & $0.21 / 0.35$ & $0.39 / 0.66$ \\
\hline
\end{tabular}

\footnotetext{
a With glucose supplemented to $60 \mathrm{~g} / \mathrm{L}$ total sugars

b $\mathrm{CSH}$ with $45 \mathrm{~g} / \mathrm{L}$ total sugars and no nutrients added

c $\mathrm{CSH}$ with $45 \mathrm{~g} / \mathrm{L}$ total sugars and $10 \mathrm{~g} / \mathrm{L} \mathrm{CaCO}_{3}$ added

${ }^{d} \mathrm{CSH}$ with glucose supplemented to $60 \mathrm{~g} / \mathrm{L}$ total sugars and no nutrients added

e $\mathrm{CSH}$ with glucose supplemented to $60 \mathrm{~g} / \mathrm{L}$ total sugars and $10 \mathrm{~g} / \mathrm{L} \mathrm{CaCO}_{3}$ added
}

of $56.5 \%$ cellulose, $4.5 \%$ hemicellulose, $34.7 \%$ acid insoluble lignin and ash. The recovery rates of solid, cellulose and hemicellulose were $57.8 \%, 79.5 \%$ and $17.1 \%$, respectively. In the $\mathrm{H}_{2} \mathrm{SO}_{4}$-pretreated $\mathrm{CSH}$, the initial concentration of total sugars was $22.0 \mathrm{~g} / \mathrm{L}(3.0 \mathrm{~g} / \mathrm{L}$ glucose, $15.5 \mathrm{~g} / \mathrm{L}$ xylose and $3.5 \mathrm{~g} / \mathrm{L}$ arabinose), and the initial concentrations of acetate, furfural and HMF as the major inhibitory compounds were 4.0, 1.5, and $0.9 \mathrm{~g} / \mathrm{L}$, respectively. After $10 \%$ inoculation, the concentration of total sugars was adjusted to $\sim 60 \mathrm{~g} / \mathrm{L}$ by adding glucose. As shown in Fig. 2 and Table 1, the regulatory impacts of PTS ${ }^{\text {GlcG }}$ on inhibitors tolerance were further investigated using the non-detoxified $\mathrm{H}_{2} \mathrm{SO}_{4}$-pretreated CSH. Similar to strain L7, strain L7(pPthl) exhibited poor cell growth and solventogenesis, wherein $2.5 \mathrm{~g} / \mathrm{L}$ butanol was produced from $15.2 \mathrm{~g} / \mathrm{L}$ total sugars (mostly glucose) with an average sugar consumption rate of $0.42 \mathrm{~g} / \mathrm{L} / \mathrm{h}$. The residual acetate decreased to $2.8 \mathrm{~g} / \mathrm{L}$. As for strain $\mathrm{L} 7(\Delta \mathrm{GlcG})$, only $12.3 \mathrm{~g} / \mathrm{L}$ total sugars $(8.8 \mathrm{~g} / \mathrm{L}$ glucose and $3.5 \mathrm{~g} / \mathrm{L}$ xylose) were utilized with an average sugar consumption rate of $0.34 \mathrm{~g} / \mathrm{L} / \mathrm{h}$, resulting in slightly decreased butanol production of $2.0 \mathrm{~g} / \mathrm{L}$. The residual acetate decreased to $1.7 \mathrm{~g} / \mathrm{L}$. It should be noted that $1.3 \mathrm{~g} / \mathrm{L}$ furfural and $0.8 \mathrm{~g} / \mathrm{L}$ HMF remained in the fermentation broth, implying poor metabolic transformation of furfural and HMF by strains L7 (pPthl) and L7( $\Delta$ GlcG).

Particularly for strain L7(GlcG), as high as $45.4 \mathrm{~g} / \mathrm{L}$ total sugars $(42.7 \mathrm{~g} / \mathrm{L}$ glucose and $2.7 \mathrm{~g} / \mathrm{L}$ xylose) was rapidly utilized within $36 \mathrm{~h}$, reaching a peak $\mathrm{OD}_{620}$ of 3.0 and an average sugar consumption rate of $1.26 \mathrm{~g} / \mathrm{L} / \mathrm{h}$. Finally, butanol production of $10.0 \mathrm{~g} / \mathrm{L}$ was achieved together with yield and productivity of $0.22 \mathrm{~g} / \mathrm{g}$ and $0.28 \mathrm{~g} / \mathrm{L} / \mathrm{h}$, respectively, which increased by $300 \%, 37.5 \%$ and $300 \%$ compared to those of strain L7(pPthl). More strikingly, the residual acetate, furfural and HMF significantly decreased to $1.3,0.3$ and $0.1 \mathrm{~g} / \mathrm{L}$, respectively, demonstrating that these pretreatment-derived inhibitors could be largely transformed into less toxic compounds by strain L7(GlcG), thus making the non-detoxified CSH culture sustainable. For example, the oxidation-reduction potential (ORP) was maintained at the range of -550 to $-520 \mathrm{mV}$, which was consistent with the active cellular metabolisms by PTS ${ }^{\text {GlcG }}$ overexpression. Correspondingly, the ORP increased rapidly after $24 \mathrm{~h}$ culture with both strains $\mathrm{L} 7(\mathrm{pPthl})$ and $\mathrm{L} 7(\Delta \mathrm{GlcG})$, wherein cell death and premature termination occurred owing to their insufficient supports on carbon, energy and reducing power. Until now, the highest butanol production of $14.5 \mathrm{~g} / \mathrm{L}$ was achieved by C. beijerinckii P260 from 

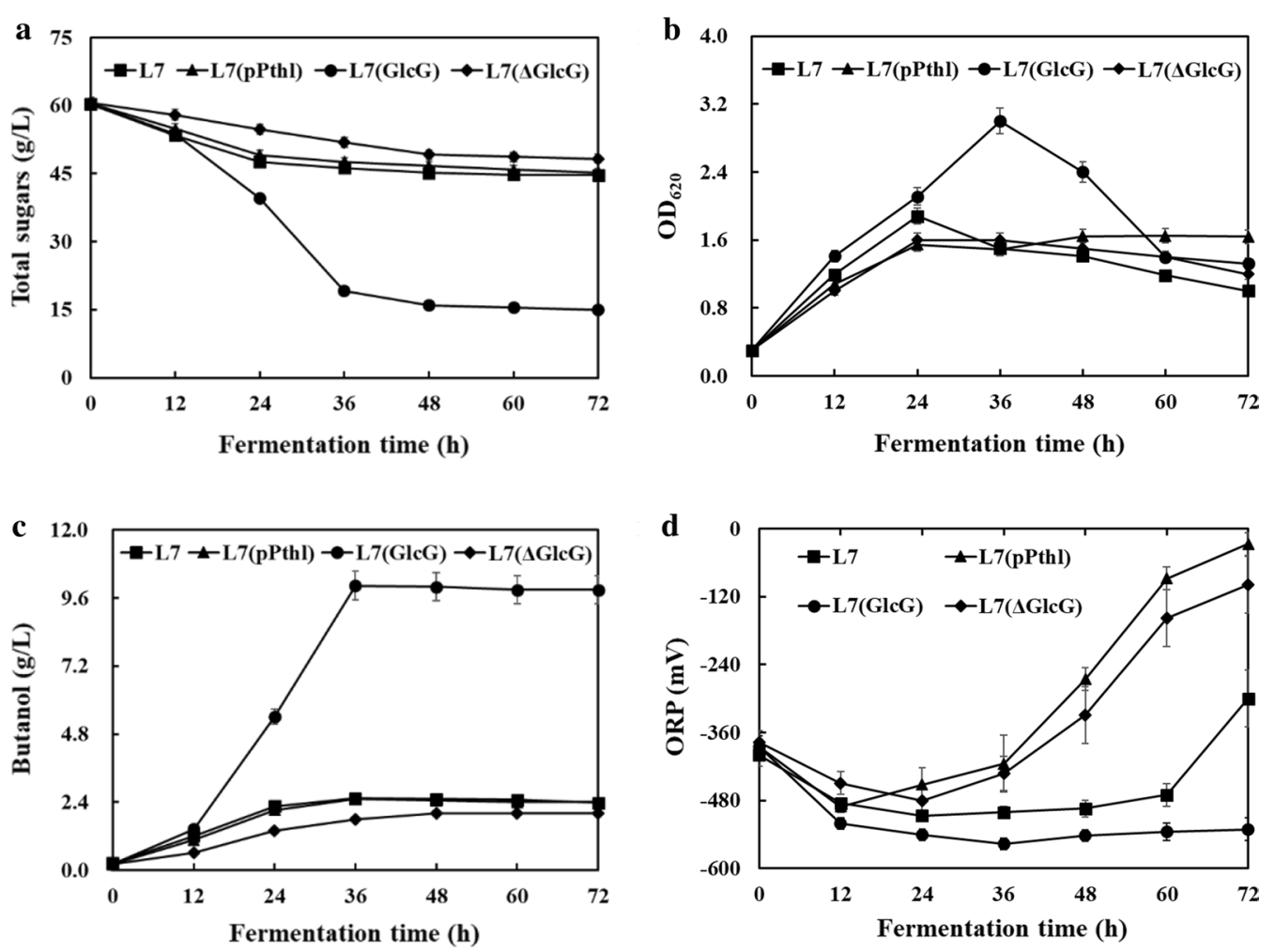

Fig. 2 PTS ${ }^{G l c G}$-mediated impact on microbial inhibitors tolerance of $C$. acetobutylicum using non-detoxified $\mathrm{H}_{2} \mathrm{SO}_{4}$-pretreated CSH. Comparative fermentation profiles of $\mathbf{a}$ total sugars; $\mathbf{b} \mathrm{OD}_{620} ; \mathbf{c}$ butanol; $\mathbf{d} \mathrm{ORP}$

detoxified $\mathrm{H}_{2} \mathrm{SO}_{4}$-pretreated $\mathrm{CSH}(60.3 \mathrm{~g} / \mathrm{L}$ total sugars by adding glucose) [18], however, butanol productivity of 0.17 was much lower than that of $0.28 \mathrm{~g} / \mathrm{L} / \mathrm{h}$ in nondetoxified CSH culture by strain L7(GlcG).

Microbial inhibitors such as furfural and 5-hydroxymethyl furfural (HMF) could be naturally transformed into less inhibitory products via the NADH-dependent metabolic detoxification process in Clostridium strains [7], which in turn hinders a metabolic shift towards solventogenesis due to excess NADH consumption in C. acetobutylicum [27]. Furthermore, the decreased ATP supply impairs cell growth and stress response, including membrane modification, heat shock proteins biosynthesis and efflux pumps. Therefore, boosting intracellular ATP and NADH supplies has been validated as a rational approach for combating these negative effects of inhibitors [2831]. For instance, glycerol as a co-substrate with glucose $(2: 1, \mathrm{~mol} / \mathrm{mol})$ could generate additional ATP and NADH and exert positive effects on cell growth, alcohol/aldehyde dehydrogenases activities and furfural/HMF transformation [12]. When subjected to $5 \mathrm{~g} / \mathrm{L}$ furfural during $\mathrm{ABE}$ fermentation, glycerol generated a 1.8-fold increase in NADH level, which accounted for 2.3-fold increase in furfural detoxification rate, glucose utilization and butanol production compared to the control without glycerol addition [12]. However, the naturally poor glycerol utilization remains a bottleneck for most solventogenic clostridia strains, leading to unsustainable ATP/ NADH support as well as unnecessary waste $[32,33]$. Therefore, the demonstrated PTS ${ }^{\text {GlcG }}$ overexpression possibly boosted intracellular ATP/NADH supplies and evoked cascading effects on inhibitors tolerance.

\section{Increased intracellular ATP and NADH supplies by overexpressing PTS ${ }^{\text {GlcG }}$}

For the sake of better understanding the intracellular energy and reducing power changes in C. acetobutylicum after PTS ${ }^{\text {GlcG }}$ overexpression, glucose-based batch culture was performed to analyze ATP and NADH levels of strains L7(pPthl) and L7(GlcG), respectively. As shown in Fig. 3, strain L7(GlcG) exhibited efficient glucose utilization and earlier solventogenesis, wherein $12.6 \mathrm{~g} / \mathrm{L}$ butanol was achieved from $59.4 \mathrm{~g} / \mathrm{L}$ glucose within only $28 \mathrm{~h}$. Therefore, as high as 2.12 and $0.45 \mathrm{~g} / \mathrm{L} / \mathrm{h}$ of glucose consumption rate and butanol productivity were also achieved, respectively, which increased by $130.4 \%$ and $125 \%$ compared to those of strain L7(pPthl). Furthermore, the exponential growth of strain L7(GlcG) was 

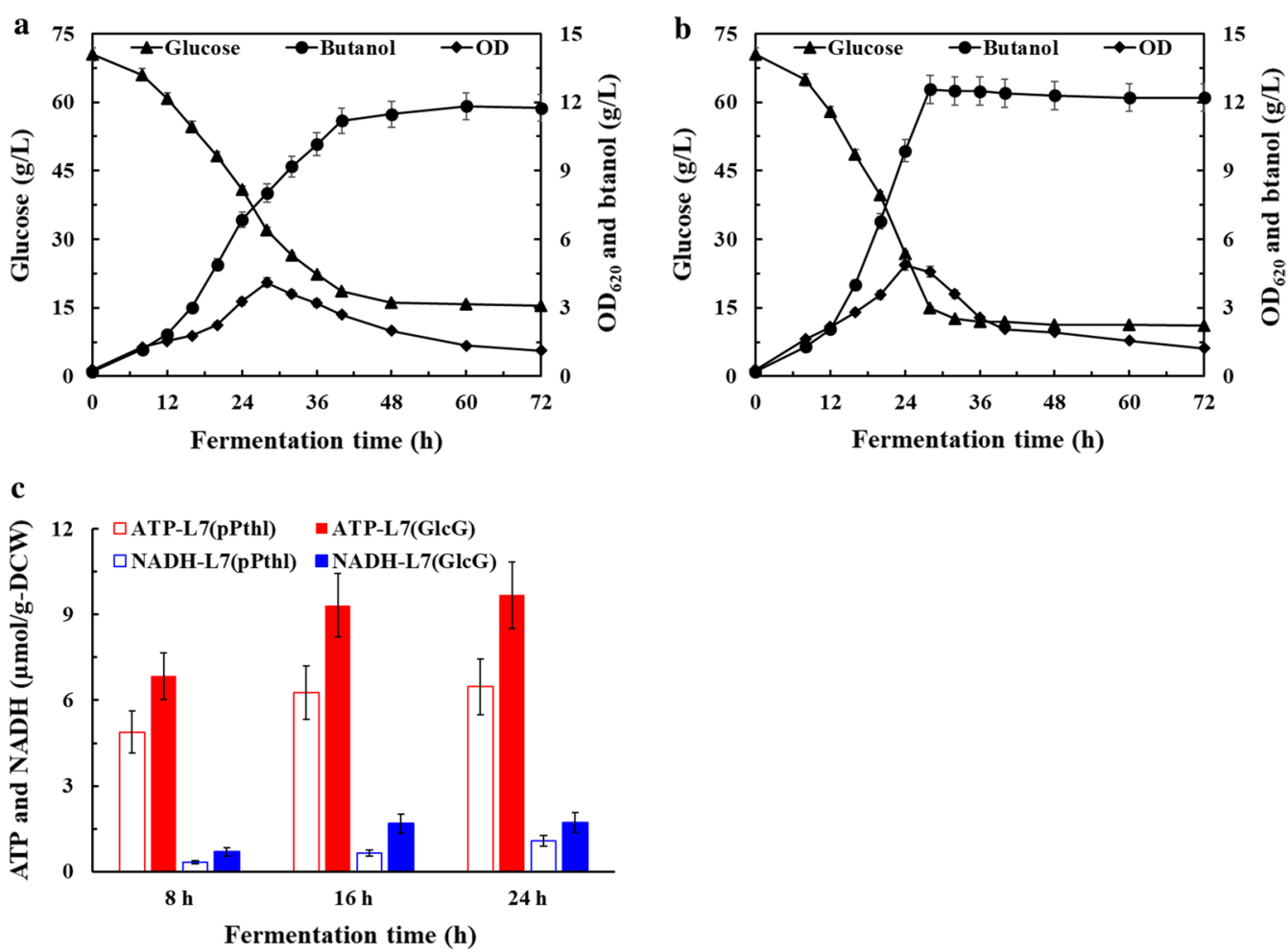

Fig. 3 PTS GlcG-mediated effects on ABE fermentation using glucose as sole carbon source. Comparative profiles of a glucose, $\mathrm{OD}_{620}$ and butanol of strain L7(pPthl); b glucose, $\mathrm{OD}_{620}$ and butanol of strain L7(GlcG); $\mathbf{c}$ ATP and NADH of strains L7(pPthl) and L7(GlcG)

significantly enhanced with a peak $\mathrm{OD}_{620}$ of 4.9 obtained at $24 \mathrm{~h}$, compared to that of 4.1 obtained at $28 \mathrm{~h}$ for strain L7(pPthl). Since strain L7(GlcG) exhibited higher fermentation efficiency than strain L7(pPthl), the sampling times were 8,16 and $24 \mathrm{~h}$ of the exponential growth phase for both strains. At the three sampling times of 8,16 and $24 \mathrm{~h}$, the ATP levels of strain L7(GlcG) were $6.85,9.33$ and $9.69 \mu \mathrm{mol} / \mathrm{g}$-DCW, respectively, which increased by $40.4 \%, 49.0 \%$ and $49.8 \%$ compared to those of strain L7(pPthl), thus leading to $23.1 \%, 55.6 \%$ and $48.5 \%$ increase on the $\mathrm{OD}_{620}$. More importantly, the $\mathrm{NADH}$ levels of strain L7(GlcG) were $0.69,1.68$ and $1.73 \mu \mathrm{mol} / \mathrm{g}$ DCW, respectively, which increased by $52.2 \%, 61.9 \%$ and $37.6 \%$ compared to those of strain L7(pPthl), which contributed to earlier solventogenesis initiation and NADHdriven inhibitors transformation. Therefore, as illustrated in Fig. 4, the experimental results demonstrated that overexpressing PTS ${ }^{\text {GlcG }}$ played pleiotropic roles regulating glucose transport and its cascading effects on cofactors generation, solventogenesis initiation and inhibitors tolerance of $C$. acetobutylicum.

High-efficient ABE fermentation from non-detoxified CSH To achieve cost-effective lignocellulosic butanol production, the enzymatically $\mathrm{H}_{2} \mathrm{SO}_{4}$-pretreated $\mathrm{CSH}$ was directly utilized for batch culture without detoxification (Fig. 5). Similarly, strains L7 and L7(pPthl) both exhibited poor fermentation performance and produced less than $3 \mathrm{~g} / \mathrm{L}$ butanol at $36 \mathrm{~h}$. As for strain L7(GlcG), 7.2 g/L butanol was produced from $34.5 \mathrm{~g} / \mathrm{L}$ total sugars within $36 \mathrm{~h}$. However, as high as $10.5 \mathrm{~g} / \mathrm{L}$ residual sugars (mainly xylose) remained in the fermentation broth. As a result of $10 \mathrm{~g} / \mathrm{L} \mathrm{CaCO}_{3}$ addition, all sugars were rapidly depleted by strain L7(GlcG) within $36 \mathrm{~h}$, wherein butanol production and productivity were further maximized to $10.0 \mathrm{~g} / \mathrm{L}$ and $0.28 \mathrm{~g} / \mathrm{L} / \mathrm{h}$. It should be noted that, under the same culture condition, butanol production was still limited to $\sim 6.0 \mathrm{~g} / \mathrm{L}$ with strains $\mathrm{L} 7$ and $\mathrm{L} 7(\mathrm{pPthl})$, respectively, implying potential redistribution of central carbon flux towards butanol biosynthesis by overexpressing PTS ${ }^{\text {GlcG }}$. Actually, $100 \mathrm{~g}$ dry corn stover yielded $\sim 45 \mathrm{~g}$ fermentable sugars (27.8 g glucose, $\sim 14 \mathrm{~g}$ xylose and $\sim 3.2 \mathrm{~g}$ arabinose) in this study. Given the fact that as high as $\sim 66 \mathrm{~g}$ fermentable sugars could be extracted from $100 \mathrm{~g}$ dry CS [4], more fermentable sugars (especially glucose) could be released from pretreated corn stover if possible. Therefore, the high concentration of total sugars was further adjusted to $60 \mathrm{~g} / \mathrm{L}$ by adding glucose after $10 \%$ inoculation. As expected, $60 \mathrm{~g} / \mathrm{L}$ total sugars were all depleted by strain $\mathrm{L} 7(\mathrm{GlcG})$ in the presence of only $10 \mathrm{~g} / \mathrm{L} \mathrm{CaCO}_{3}$. 


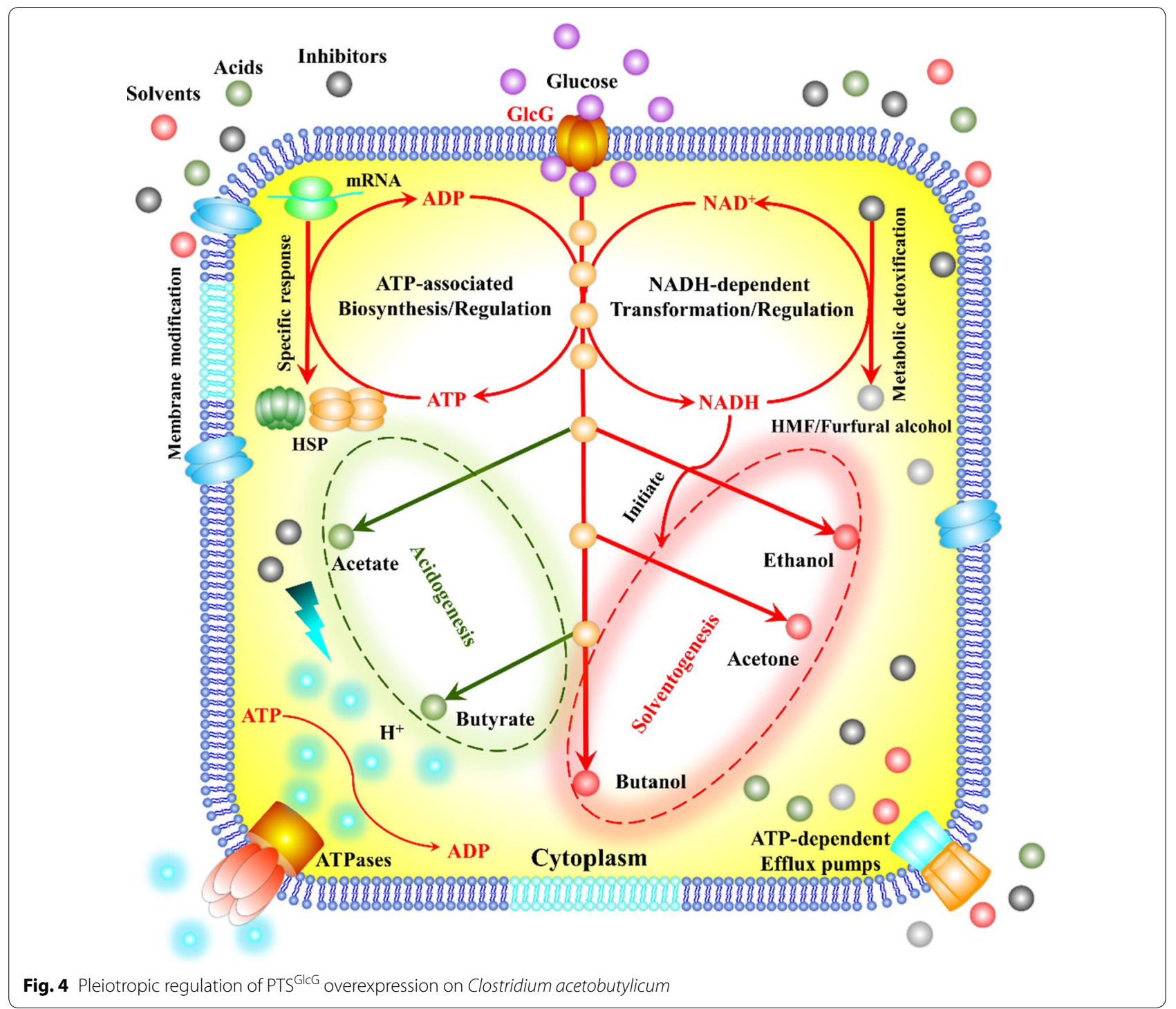

Butanol production and productivity of $12.5 \mathrm{~g} / \mathrm{L}$ and $0.39 \mathrm{~g} / \mathrm{L} / \mathrm{h}$ could be achieved, which increased by $316.7 \%$ and $387.5 \%$ compared to those of strain L7(pPthl), making the detoxification process, wastewater generation and medium optimization unnecessary for non-detoxified $\mathrm{CSH}$ culture.

As summarized in Table 2, despite considerable efforts on improving CS-based ABE fermentation [10, 18, 34-36], high-efficient CSH culture remains a significant issue in synthetical consideration of sugar utilization, butanol production and productivity. For instance, Qureshi et al. reported that the highest butanol production of $14.5 \mathrm{~g} / \mathrm{L}$ was achieved with productivity of $0.17 \mathrm{~g} / \mathrm{L} / \mathrm{h}$ by C. beijerinckii P260 using detoxified $\mathrm{H}_{2} \mathrm{SO}_{4}$-pretreated $\mathrm{CSH}$ [18]. Zhang et al. reported that $7.1 \mathrm{~g} / \mathrm{L}$ butanol was produced with much lower productivity of $0.10 \mathrm{~g} / \mathrm{L} / \mathrm{h}$ from detoxified $\mathrm{CSH}$ by $C$. acetobutylicum ATCC 824 [36]. Until recently, butanol productivity was improved to $0.19 \mathrm{~g} / \mathrm{L} / \mathrm{h}$ using detoxified enzymatically $\mathrm{NaOH}$-pretreated $\mathrm{CSH}$ by $\mathrm{C}$. beijerinckii CC101 [37]. As reported by Gao et al., the butanoltolerant $C$. acetobutylicum strain 206 was screened by NTG mutagenesis and proven to be robust for lignocellulosic $A B E$ fermentation, wherein butanol productivity up to $0.14 \mathrm{~g} / \mathrm{L} / \mathrm{h}$ could be achieved using non-detoxified enzymatically $\mathrm{NaOH}$-pretreated $\mathrm{CSH}$ [38]. However, no solventogenic clostridia strains to date are available for high-efficient CSH culture. Therefore, the demonstrated PTS ${ }^{\text {GlcG }}$ overexpression in this study was validated as a feasible engineering approach for high-efficient butanol production from lignocellulosic feedstocks without detoxification or wastewater generation. 

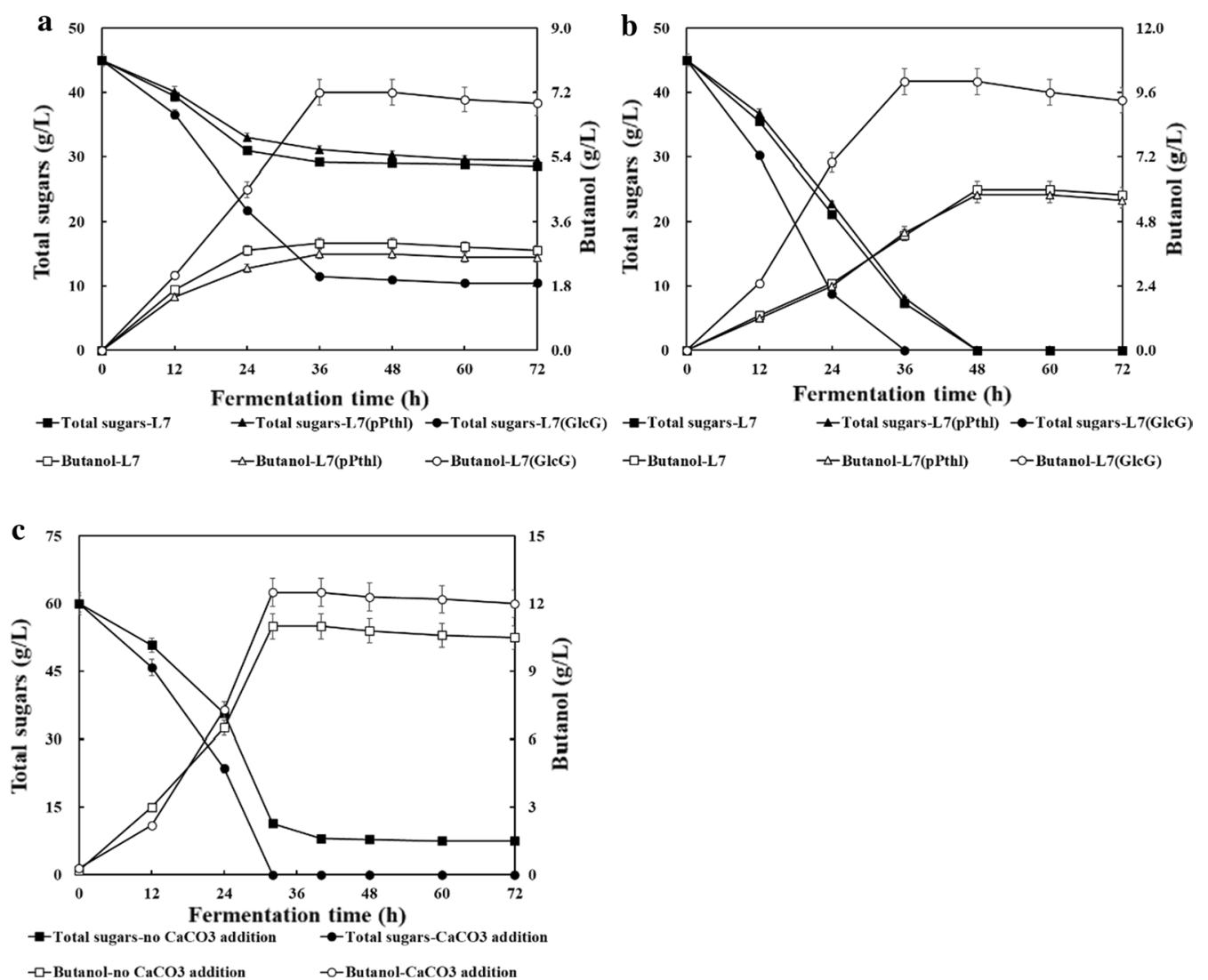

Fig. 5 Batch $\mathrm{ABE}$ fermentation using non-detoxified enzymatically $\mathrm{H}_{2} \mathrm{SO}_{4}$-pretreated $\mathrm{CSH}$. Fermentation conditions of a $45 \mathrm{~g} / \mathrm{L}$ total sugars; $\mathbf{b}$ $45 \mathrm{~g} / \mathrm{L}$ total sugars with $10 \mathrm{~g} / \mathrm{L} \mathrm{CaCO}_{3}$ addition; c $60 \mathrm{~g} / \mathrm{L}$ total sugars with/without $10 \mathrm{~g} / \mathrm{L} \mathrm{CaCO}_{3}$ addition

Table 2 Comparisons of batch ABE fermentation using detoxified or non-detoxified CSH

\begin{tabular}{|c|c|c|c|c|c|c|}
\hline \multirow[t]{2}{*}{ Strain } & \multirow{2}{*}{$\begin{array}{l}\text { Pretreatment } \\
\text { method }\end{array}$} & \multirow{2}{*}{$\begin{array}{l}\text { Detoxification } \\
\text { method }\end{array}$} & \multicolumn{3}{|l|}{ Products } & \multirow[t]{2}{*}{ References } \\
\hline & & & Butanol/ABE (g/L) & Yield $(g / g)$ & Productivity (g/L/h) & \\
\hline $\begin{array}{l}\text { C. acetobutylicum } \\
\text { ATCC } 824\end{array}$ & $\begin{array}{l}\text { Alkaline twin-screw } \\
\text { extrusion }\end{array}$ & Washing & $7.1 / 11.2$ & $0.18 / 0.29$ & $0.10 / 0.16$ & Zhang et al. [36] \\
\hline $\begin{array}{l}\text { C. acetobutylicum } \\
\text { ATCC } 824\end{array}$ & Steam explosion & Activated charcoal & $\mathrm{NA} / 12.4$ & NA/0.30 & $\mathrm{NA} / 0.17$ & Wang and Chen [35] \\
\hline C. beijerinckii P260 & $1 \%(\mathrm{v} / \mathrm{v}) \mathrm{H}_{2} \mathrm{SO}_{4}$ & Overliming & $14.5 / 26.3$ & $0.24 / 0.44$ & $0.17 / 0.31$ & Qureshi et al. [18] \\
\hline C. beijerinckii P260 & $1 \%(\mathrm{v} / \mathrm{v}) \mathrm{H}_{2} \mathrm{SO}_{4}$ & Overliming & NA/24.4 & NA/0.44 & NA/0.30 & Qureshi et al. [34] \\
\hline C. beijerinckii CC101 & $2 \%(\mathrm{v} / \mathrm{v}) \mathrm{NaOH}$ & Washing & $11.2 / 19.8$ & $0.28 / 0.49$ & $0.19 / 0.33$ & Xue et al. [37] \\
\hline $\begin{array}{l}\text { C. acetobutylicum } \\
\text { ATCC } 824\end{array}$ & Steam explosion & ND & $2.2 / 3.7$ & NA/NA & $0.03 / 0.05$ & Wang and Chen [35] \\
\hline $\begin{array}{l}\text { C. acetobutylicum } \\
\text { strain } 206\end{array}$ & $2 \%(\mathrm{v} / \mathrm{v}) \mathrm{NaOH}$ & ND & $9.8 / 15.4$ & $0.26 / 0.41$ & $0.14 / 0.21$ & Gao et al. [38] \\
\hline C. beijerinckii P260 & $1 \%(\mathrm{v} / \mathrm{v}) \mathrm{H}_{2} \mathrm{SO}_{4}$ & ND & No fermentation & & & Qureshi et al. [18] \\
\hline C. acetobutylicum L7 & $1 \%(\mathrm{v} / \mathrm{v}) \mathrm{H}_{2} \mathrm{SO}_{4}$ & ND & $3.0 / 4.8$ & $0.18 / 0.29$ & $0.08 / 0.13$ & This study \\
\hline $\begin{array}{l}\text { C. acetobutylicum } \\
\text { L7(GlcG) }\end{array}$ & $1 \%(\mathrm{v} / \mathrm{v}) \mathrm{H}_{2} \mathrm{SO}_{4}$ & ND & $12.5 / 21.0$ & $0.21 / 0.35$ & $0.39 / 0.66$ & This study \\
\hline
\end{tabular}

NA not available, ND not detoxified 


\section{Conclusions}

In this study, PTS ${ }^{\text {GlcG }}$-engineered $C$. acetobutylicum strains were constructed via gene $g l c G$ overexpression and knockout to address the major problems during non-detoxified CSH culture. The PTS ${ }^{\mathrm{GlcG}}$-overexpressing strain exhibited remarkable improvements in glucose utilization, exponential growth and inhibitors tolerance, which was ascribed to efficient glucose transport but also its cascading effects on intracellular ATP and NADH generation, solventogenesis initiation and inhibitors tolerance. Finally, $12.5 \mathrm{~g} / \mathrm{L}$ butanol was achieved within $32 \mathrm{~h}$ of non-detoxified $\mathrm{CSH}$ culture, resulting in significantly improved butanol productivity up to $0.39 \mathrm{~g} / \mathrm{L} / \mathrm{h}$, and thus making butanol production from lignocellulosic feedstocks more economically sustainable and environmentally friendly.

\section{Materials and methods}

\section{Bacterial strains, primers and plasmids}

All bacterial strains and plasmids used in this study are listed in Table 3. Generally, strain C. acetobutylicum L7, adapted from the wild-type strain C. acetobutylicum ATCC 824 as previously reported [21], was

Table 3 Bacterial strains and plasmids used in this study

\begin{tabular}{|c|c|c|}
\hline Strains/plasmids & Relevant characteristics & Source/references \\
\hline \multicolumn{3}{|l|}{ Bacterial strains } \\
\hline \multicolumn{3}{|l|}{ E. coli } \\
\hline $\mathrm{DH} 5 \mathrm{a}$ & $\begin{array}{l}\text { Host cells for gene cloning and } \\
\text { plasmids amplification }\end{array}$ & Invitrogen \\
\hline $\mathrm{DH} 10 \mathrm{~B}$ & $\begin{array}{l}\text { Strain used to methylate the } \\
\text { vector }\end{array}$ & Invitrogen \\
\hline \multicolumn{3}{|l|}{ C. acetobutylicum } \\
\hline ATCC 824 & Wild-type strain & ATCC \\
\hline $\mathrm{L} 7$ & $\begin{array}{l}\text { Adapted from C. acetobutylicum } \\
\text { ATCC } 824\end{array}$ & {$[21]$} \\
\hline L7(pPthl) & $\begin{array}{l}\text { Control strain, L7 containing } \\
\text { the control plasmid pIMP1- } \\
\text { Pthl }\end{array}$ & This study \\
\hline $\mathrm{L} 7(\mathrm{G} \mid \mathrm{CG})$ & $\begin{array}{l}\text { L7 containing the plasmid } \\
\text { pIMP1-Pthl-glcG }\end{array}$ & This study \\
\hline $\mathrm{L} 7(\triangle \mathrm{GlCG})$ & $\begin{array}{l}\text { PTS } \\
\text { intron-deficient strain via } \\
\text { inediated knockout }\end{array}$ & This study \\
\hline \multicolumn{3}{|l|}{ Plasmids } \\
\hline pAN1 & Ф3TI, p15A origin; Spe $e^{r}$ & {$[39]$} \\
\hline PSY6 & Group II intron, ItrA & {$[41]$} \\
\hline pIMP1 & $\begin{array}{l}\text { Ampri }{ }^{r} \text {;LS } S^{r} \text {; repL, ColE1 origin, } \\
\text { shuttle vector }\end{array}$ & {$[11]$} \\
\hline plMP1-Pthl & $\begin{array}{l}\text { Control vector carrying th/ pro- } \\
\text { moter, derived from pIMP1 }\end{array}$ & {$[11]$} \\
\hline plMP1-Pthl-glcG & $\begin{array}{l}\text { Derived from plMP1-Pthl with } \\
\text { glcG overexpression in L7 }\end{array}$ & This study \\
\hline PSY-GICG & $\begin{array}{l}\text { Vector for intron insertion at } \\
269 / 270 \text { bp of glcG in L7 }\end{array}$ & This study \\
\hline
\end{tabular}

used for constructing the control and PTS-engineered strains. Strains E. coli DH5 $\alpha$ and DH10B cultured with LB medium or agar containing $10 \mu \mathrm{g} / \mathrm{mL}$ ampicillin and $50 \mu \mathrm{g} / \mathrm{mL}$ spectinomycin were used for plasmids amplification and in vivo methylation. Based on the C. acetobutylicum ATCC 824 genome, gene glcG synthesized by Sangon (Shanghai, China) was digested with the SalI/KpnI restriction sites and then ligated into the control plasmid

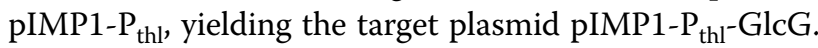
Plasmids pIMP1-P thl and pIMP1-P thl -GlcG were first methylated in E. coli DH10B and then electroporated into strain L7, respectively, according to the standard protocols [39]. The resulting cells were then cultured on RCM (Thermo Fisher, Oxoid Ltd.) agar containing $50 \mu \mathrm{g} / \mathrm{mL}$ erythromycin for single colony selection, yielding the control strain L7(pPthl) and PTS ${ }^{\text {GlcG }}$-overexpressing strain L7(GlcG). According to the method described by Xiao et al., the PTS ${ }^{\text {GlcG }}$-deficient strain L7 $(\Delta$ GlcG) was constructed via intron-mediated knockout system with an intron inserted at 269/270 bp of gene glcG [11], and all the related primers were synthesized by Sangon (see Additional file 1: Table S1). All the commercial enzymes were purchased from New England Biolabs (Beverly, MA).

\section{Acid pretreatment of corn stover}

The CS (Pioneer variety) used in this study was obtained from a local farmer in Shandong and milled into 1-2 $\mathrm{mm}$ particles using a hammer mill. As documented by Malmierca et al., one hundred grams of milled CS was soaked with $1 \mathrm{~L} 1 \%(\mathrm{v} / \mathrm{v})$ dilute $\mathrm{H}_{2} \mathrm{SO}_{4}$ solution in a stirred tank at $121{ }^{\circ} \mathrm{C}$ for $90 \mathrm{~min}$, followed by cooling to room temperature and adjusting $\mathrm{pH}$ to 5.0 using $10 \mathrm{M} \mathrm{NaOH}$ [40]. The initial concentration of total sugars in the $\mathrm{H}_{2} \mathrm{SO}_{4}$-pretreated $\mathrm{CSH}$ was $22 \mathrm{~g} / \mathrm{L}$, which was further added to $60 \mathrm{~g} / \mathrm{L}$ with extra glucose when necessary.

\section{Enzymatic hydrolysis of acid-pretreated corn stover}

As optimized by Xue et al., the resulting $\mathrm{H}_{2} \mathrm{SO}_{4}$-pretreated CS mixture containing $30 \mathrm{mM}$ citrate was hydrolyzed using cellulase (Tianjin Novozymes Biotechnology, China) with $20 \mathrm{FPU} / \mathrm{g}-\mathrm{CS}$ at $50{ }^{\circ} \mathrm{C}, \mathrm{pH} 4.8$ and $200 \mathrm{rpm}$ for $72 \mathrm{~h}$ [37]. The enzymatically $\mathrm{H}_{2} \mathrm{SO}_{4}$-pretreated $\mathrm{CSH}$ was obtained by centrifugation at $8000 \times g$ for $5 \mathrm{~min}$ to remove sediments, and then stored at $4{ }^{\circ} \mathrm{C}$ for subsequent batch culture without detoxification process or medium optimization. Followed by $10 \%$ inoculation during $\mathrm{CSH}$ culture, the initial concentration of total sugars was $\sim 45 \mathrm{~g} / \mathrm{L}$, which was added to $60 \mathrm{~g} / \mathrm{L}$ with extra glucose when necessary.

\section{Media and culture conditions}

The media for pre-culture and seed culture were as previously described [21, 23]. The standard fermentation 
medium is composed of $(\mathrm{g} / \mathrm{L})$ : glucose or glucose/xylose mixture $(2: 1, \mathrm{w} / \mathrm{w}) 70.0$, yeast extract $2.0, \mathrm{~K}_{2} \mathrm{HPO}_{4} 0.50$, $\mathrm{KH}_{2} \mathrm{PO}_{4} \quad 0.50, \mathrm{MgSO}_{4} \cdot 7 \mathrm{H}_{2} \mathrm{O} \quad 0.20, \mathrm{MnSO}_{4} \cdot \mathrm{H}_{2} \mathrm{O} \quad 0.10$, $\mathrm{FeSO}_{4} \cdot 7 \mathrm{H}_{2} \mathrm{O}$ 0.01, $\mathrm{CH}_{3} \mathrm{COONH}_{4}$ 3.22, para-aminobenzoic acid 0.01 and biotin 0.01 . The CSHs mentioned above were directly utilized for batch $\mathrm{ABE}$ fermentation, respectively. All CSHs and media were sterilized at $121^{\circ} \mathrm{C}$ for $15 \mathrm{~min}$, followed by cooling to room temperature and added with $10 \mu \mathrm{g} / \mathrm{mL}$ erythromycin when necessary. The initial $\mathrm{pH}$ for batch culture was adjusted to 5.5 using $3 \mathrm{M}$ $\mathrm{H}_{2} \mathrm{SO}_{4}$ or $3 \mathrm{M} \mathrm{NaOH}$ after $10 \%$ inoculation. All chemical reagents used in this study were of analytical grade or equivalent and purchased from Sangon.

\section{Batch ABE fermentation}

Batch $\mathrm{ABE}$ fermentation was carried out in a stirred tank containing $\mathrm{CSH}$ or standard medium under anaerobic conditions as previously described [21]. After 10\% inoculation, the initial fermentation $\mathrm{pH}$ was adjusted to 5.5 using $3 \mathrm{M} \mathrm{H}_{2} \mathrm{SO}_{4}$ or $\mathrm{NaOH}$. All the experiments were triplicated and samples were taken for analyzing cell growth, residual sugar(s), acids and ABE production. Particularly, intracellular ATP and NADH were quantified during batch culture using non-detoxified $\mathrm{H}_{2} \mathrm{SO}_{4}$-pretreated $\mathrm{CSH}$.

\section{Analysis of intracellular ATP and NADH}

During batch culture using glucose as the sole carbon source, C. acetobutylicum cells were collected at 8,16 and $24 \mathrm{~h}$ by centrifugation at $10,000 \times g$ for $3 \mathrm{~min}$ at $-10^{\circ} \mathrm{C}$. The resulting cell pellets were quenched immediately with $500 \mu \mathrm{L}$ solution mixture of methanol, acetonitrile and water (40:40:20, v/v, $-40{ }^{\circ} \mathrm{C}$ ), and then frozen in liquid nitrogen for preparing crude extracts. According to our previous study [22], LC-MS/MS analysis was conducted for ATP quantification with an ACCELA HPLC system (Thermo Scientific, CA) equipped with an XBridge BEH Amide column (100 mm $\times 2.1 \mathrm{~mm}$ I.D., $2.5 \mu \mathrm{m}$, Waters, Ireland). Mass monitoring was achieved using a TSQ Quantum Ultra triple quadrupole mass analyzer (Thermo Scientific, CA) equipped with a heated electrospray ionization source (HESI). NADH assay was performed using a commercial kit (Sigma, MO). Cell pellets were first lysed using a Qiagen Tissue Lyser LT (Qiagen, Germany) at 50 oscillations/s for $3 \mathrm{~min}$ in the NADH extraction buffers (Sigma, MO), the resulting lysate was then used for NADH quantification at $450 \mathrm{~nm}$ with an $\mathrm{iMark}^{\mathrm{TM}}$ microplate reader (Bio-Rad, CA).

\section{Analytical methods}

As previously described, cell growth was measured at $620 \mathrm{~nm}$ using a spectrophotometer (Thermo Spectronic, USA) [22]. The chemical compositions of unpretreated and pretreated CS solids were analyzed according to Laboratory Analytical Procedures [19].
The total sugars in CSH were determined by 3,5-dinitrosalicylic acid (DNS) method at $540 \mathrm{~nm}$ using the spectrophotometer. ABE were determined by a gas chromatography (Agilgent 6890A GC). Sugars (glucose, xylose and arabinose), acids (acetate and butyrate) and major inhibitors (furfural and HMF) were analyzed by a highperformance liquid chromatography (Waters 1525 HPLC). All the standard chemicals of sugars, acids and ABE were of quality HPLC gradient grade and purchased from Sigma-Aldrich (Saint-Louis, Missouri, USA). The butanol or $\mathrm{ABE}$ yield $\left(Y_{\mathrm{B} / \mathrm{ABE}}\right)$ was calculated as total butanol or $\mathrm{ABE}$ produced divided by the total sugars used and is expressed in $\mathrm{g} / \mathrm{g}$. The butanol or $\mathrm{ABE}$ productivity $\left(P_{\mathrm{B} / \mathrm{ABE}}\right)$ was calculated as total butanol or ABE produced divided by the fermentation time used and is expressed in $\mathrm{g} / \mathrm{L} / \mathrm{h}$.

\section{Supplementary information}

Supplementary information accompanies this paper at https://doi. org/10.1186/s13068-019-1604-7.

Additional file 1: Table S1. Primers used in this study.

\section{Abbreviations}

CSH: Corn stover hydrolysate; PTS: Phosphotransferase system; ABE: Acetonebutanol-ethanol; RCM: Reinforced Clostridium medium; ATP: Adenosine triphosphate; $\mathrm{NADH}$ : Nicotinamide adenine dinucleotide.

\section{Acknowledgements}

Not applicable.

\section{Authors' contributions}

YDW and DJZ designed all the experiments. YDW constructed the

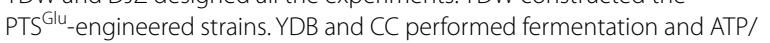
$\mathrm{NADH}$ analysis. YDW and XC drafted the manuscript and involved data analysis. LJC and FWB revised the manuscript. All authors read and approved the final manuscript.

\section{Funding}

This study was supported by the National Natural Science Foundation of China with Grant Numbers (21808027, 41861124004 \& 21878035), the Open Funding Project of the State Key Laboratory of Bioreactor Engineering, the National Key R\&D Program of China (2018YFB1501703), the Liaoning Revitalization Talents Program (XLYC1807269), the Dalian Science and Technology Innovation Project (2018J12SN074), the Liaoning Innovative Talent Support Program (LR2017005), the Youth Science and Technology Star Project of Dalian (2017RQ003), and the Fundamental Research Funds for the Central Universities (DUT17RC(4)006 \& DUT19ZD213).

\section{Availability of data and materials}

All data generated or analyzed in this study are included in this article and its Additional information files. The datasets used and/or analyzed during the current study are available from the corresponding author on reasonable request.

\section{Ethics approval and consent to participate} Not applicable.

\section{Consent for publication}

All authors provide consent for publication of the manuscript in Biotechnology for Biofuels.

\section{Competing interests}

The authors declare that they have no competing interests. 


\section{Author details}

${ }^{1}$ School of Bioengineering, Dalian University of Technology, No 2 Linggong Road, Dalian 116024, China. ${ }^{2}$ State Key Laboratory of Bioreactor Engineering, East China University of Science and Technology, Shanghai 200237, China. ${ }^{3}$ School of Life Sciences and Biotechnology, Shanghai Jiao Tong University, Shanghai 200240, China.

Received: 4 June 2019 Accepted: 29 October 2019

Published online: 07 November 2019

\section{References}

1. Xue C, Zhao XQ, Liu CG, et al. Prospective and development of butanol as an advanced biofuel. Biotechnol Adv. 2013;31(8):1575-84.

2. Xue C, Zhao JB, Chen L, Yang ST, Bai FW. Recent advances and state-of-theart strategies in strain and process engineering for biobutanol production by Clostridium acetobutylicum. Biotechnol Adv. 2017;35:310-22.

3. Ranjan A, MoholkarVS. Biobutanol: science, engineering, and economics. Int J Energy Res. 2012;36(3):277-323.

4. Baral NR, Slutzky JL, Shah A, et al. Acetone-butanol-ethanol fermentation of corn stover: current production methods, economic viability, and commercial use. FEMS Microbiol Lett. 2016;363:fnw033.

5. Gottumukkala LD, Haigh K, Görgens J. Trends and advances in conversion of lignocellulosic biomass to biobutanol: microbes, bioprocesses and industrial viability. Renew Sust Energy Rev. 2017;76:963-73.

6. Li J, Baral NR, Jha AK. Acetone-butanol-ethanol fermentation of corn stover by Clostridium species: present status and future perspectives. World J Microbiol Biotechnol. 2013;30(4):1145-57.

7. Baral NR, Shah A. Microbial inhibitors: formation and effects on acetonebutanol-ethanol fermentation of lignocellulosic biomass. Appl Microbiol Biotechnol. 2014;98:9151-72.

8. Jönsson $\sqcup$, Martín C. Pretreatment of lignocellulose: formation of inhibitory by-products and strategies for minimizing their effects. Bioresour Technol. 2016;199:103-12.

9. Yang ST, Zhao JB. Adaptive engineering of Clostridium for increased butanol production. 2013; US Patent 8450093

10. Guo T, Tang Y, Zhang QY, et al. Clostridium beijerinckii mutant with high inhibitor tolerance obtained by low-energy ion implantation. J Ind Microbiol Biotechnol. 2012;39:401-7.

11. Xiao H, Gu Y, Ning YY, et al. Confirmation and elimination of xylose metabolism bottlenecks in glucose phosphoenolpyruvate-dependent phosphotransferase system-deficient Clostridium acetobutylicum for simultaneous utilization of glucose, xylose, and arabinose. Appl Environ Microb. 2011;77:7886-95.

12. Ujor V, Agu CV, Gopalan V, et al. Glycerol supplementation of the growth medium enhances in situ detoxification of furfural by Clostridium beijerinckii during butanol fermentation. Appl Microbiol Biotechnol. 2014;98(14):6511-21.

13. Grimmler C, Held C, Liebl W, et al. Transcriptional analysis of catabolite repression in Clostridium acetobutylicum growing on mixtures of D-glucose and D-xylose. J Biotechnol. 2010;150:315-23.

14. Ren C, Gu Y, Hu S, et al. Identification and inactivation of pleiotropic regulator $\mathrm{CcpA}$ to eliminate glucose repression of xylose utilization in Clostridium acetobutylicum. Metab Eng. 2010;12(5):446-54.

15. Jin L, Zhang H, Chen L, et al. Combined overexpression of genes involved in pentose phosphate pathway enables enhanced D-xylose utilization by Clostridium acetobutylicum. J Biotechnol. 2014;173:7-9.

16. GuY, Li J, Zhang L, et al. Improvement of xylose utilization in Clostridium acetobutylicum via expression of the talA gene encoding transaldolase from Escherichia coli. J Biotechnol. 2009;143(4):284-7.

17. Gu Y, Ding Y, Ren C, et al. Reconstruction of xylose utilization pathway and regulons in Firmicutes. BMC Genomics. 2010;11(1):255.

18. Qureshi N, Saha BC, Hector RE, et al. Production of butanol (a biofuel) from agricultural residues: part II-use of corn stover and switchgrass hydrolysates. Biomass Bioenergy. 2010;34:566-71.

19. Xue C, Zhang XT, Wang JF, et al. The advanced strategy for enhancing biobutanol production and high-efficient product recovery with reduced wastewater generation. Biotechnol Biofuels. 2017;10:148.

20. Gheshlaghi R, Scharer JM, Moo-Young M, et al. Metabolic pathways of clostridia for producing butanol. Biotechnol Adv. 2009;27(6):764-81.
21. Wu YD, Xue C, Chen LJ, et al. Effect of zinc supplementation on acetonebutanol-ethanol fermentation by Clostridium acetobutylicum. J Biotechnol. 2013;165:18-21.

22. Wu YD, Xue C, Chen $L$, et al. Transcriptional analysis of micronutrient zincassociated response for enhanced carbohydrate utilization and earlier solventogenesis in Clostridium acetobutylicum. Sci Rep. 2015;5:16598.

23. Wu YD, Xue $C$, Chen $L$, et al. Synergistic effect of calcium and zinc on glucose/xylose utilization and butanol tolerance of Clostridium acetobutylicum. FEMS Microbiol Lett. 2016;363:fnw023.

24. Han B, Ujor V, Lai LB, et al. Use of proteomic analysis to elucidate the role of calcium on acetone-butanol-ethanol (ABE) fermentation in Clostridium beijerinckii NCIMB 8052. Appl Environ Microbiol. 2013;79:282-93.

25. Richmond C, Han B, Ezeji TC. Stimulatory effects of calcium carbonate on butanol production by solventogenic Clostridium species. Cont J Microbiol. 2011;5:18-28.

26. El Kanouni A, Zerdani I, Zaafa S, et al. The improvement of glucose/xylose fermentation by Clostridium acetobutylicum using calcium carbonate. World J Microbiol Biotechnol. 1998;14:431-5.

27. Zhang Y, Han B, Ezeji TC. Biotransformation of furfural and 5-hydroxymethyl furfural (HMF) by Clostridium acetobutylicum ATCC 824 during butanol fermentation. N Biotechnol. 2012;29(3):345-51.

28. Ventura JR, Hu H, Jahng D. Enhanced butanol production in Clostridium acetobutylicum ATCC 824 by double overexpression of 6-phosphofructokinase and pyruvate kinase genes. Appl Microbiol Biotechnol. 2013;97(16):7505-16.

29. Liu D, Yang Z, Wang P, et al. Towards acetone-uncoupled biofuels production in solventogenic Clostridium through reducing power conservation. Metab Eng. 2018;47:102-12.

30. Agu CV, Ujor V, Ezeji TC. Metabolic engineering of Clostridium beijerinckii to improve glycerol metabolism and furfural tolerance. Biotechnol Biofuels. 2019;12:50.

31. Liu J, Guo T, Wang D, et al. Enhanced butanol production by increasing $\mathrm{NADH}$ and ATP levels in Clostridium beijerinckii NCIMB 8052 by insertional inactivation of Cbei_4110. Appl Microbiol Biotechnol. 2016;100(11):4985-96.

32. Girbal L, Croux C, Vasconcelos I, et al. Regulation of metabolic shifts in Clostridium acetobutylicum ATCC 824. FEMS Microbiol Rev. 1995;17(3):287-97.

33. Vasconcelos I, Girbal L, Soucaille P. Regulation of carbon and electron flow in Clostridium acetobutylicum grown in chemostat culture at neutral pH on mixtures of glucose and glycerol. J Bacteriol. 1994;176(5):1443-50.

34. Qureshi N, Cotta MA, Saha BC. Bioconversion of barley straw and corn stover tobutanol (a biofuel) in integrated fermentation and simultaneous product recovery bioreactors. Food Bioprod Process. 2014;92:298-308.

35. Wang $L$, Chen HZ. Increased fermentability of enzymatically hydrolyzed steam-exploded corn stover for butanol production by removal of fermentation inhibitors. Process Biochem. 2011;46:604-7.

36. Zhang YD, Hou TG, Li B, et al. Acetone-butanol-ethanol production from corn stover pretreated by alkaline twin-screw extrusion pretreatment. Bioprocess Biosyst Eng. 2014;37:913-21.

37. Xue C, Wang ZX, Wang SD, et al. The vital role of citrate buffer in acetonebutanol-ethanol (ABE) fermentation using corn stover and high-efficient product recovery by vapor stripping-vapor permeation (VSVP) process. Biotechnol Biofuels. 2016;9:146.

38. Gao K, LiY, Tian S, et al. Screening and characteristics of a butanol-tolerant strain and butanol production from enzymatic hydrolysate of $\mathrm{NaOH}$-pretreated corn stover. World J Microbial Biotechnol. 2012;28:2963-71.

39. Mermelstein LD, Papoutsakis ET. In vivo methylation in Escherichia coli by the Bacillus subtilis phage phi 3T I methyltransferase to protect plasmids from restriction upon transformation of Clostridium acetobutylicum ATCC 824. Appl Environ Microbiol. 1993;59:1077-81.

40. Malmierca S, Díez-Antolínez R, Paniagua Al, et al. Technoeconomic study of biobutanol $A B$ production. 1. Biomass pretreatment and hydrolysis. Ind Eng Chem Res. 2017:56(6):1518-24.

41. Seno ET, Chater KF. Glycerol catabolic enzymes and their regulation in wild-type and mutant strains of Streptomyces coelicolor A3(2). J Gen Microbiol. 1983;129:1403-13.

\section{Publisher's Note}

Springer Nature remains neutral with regard to jurisdictional claims in published maps and institutional affiliations. 